\title{
Prototype Alat Penyiram Tanaman Otomatis dengan Sensor Kelembaban dan Suhu Berbasis Arduino
}

\author{
Shamaratul Fuadi ${ }^{1}$, Oriza Candra ${ }^{2}$ \\ 1,2 Universitas Negeri Padang \\ Jl. Prof Dr. Hamka Air Tawar, Padang, Indonesia \\ shamaratul@gmail.com1 ${ }^{1}$ orizacandra@ft.unp.ac.id ${ }^{2}$
}

\begin{abstract}
Quality plants are produced by observing soil moisture and plant temperature. Plants humidity and temperature are affected by plant irrigations system. Therefore, this Final Project aims to make a plant sprinklers that can control water discharge according to plant needs. Using the Soilmoisture Sensor which functions as a reader of plant soil moisture and DHT11 as a reader of the air temperature around the plant. Then the relay module functions to activate and deactivate the water pump. LCD is used to display the data results and the ESP8266 Module is also used as a display of the results of sensor data, which will be sent to the thingspeak.com website.
\end{abstract}

Keywords-Arduino Uno, Soilmoisture Sensor, DHT11 sensor, Relay, 12 VDC water pump, ESP8266 module, LCD, website.

\begin{abstract}
Abstrak - Tanaman yang berkualitas dihasilkan dengan memperhatikan kelembaban tanah dan suhu tanaman. Kelembaban dan suhu tanaman dipengaruhi oleh adanya pengairan terhadap tanaman. Untuk itu Tugas Akhir ini bertujuan membuat alat penyiram tanaman yang dapat mengontrol debit air yang keluar sesuai kebutuhan tanaman. Dimana menggunakan Sensor Soilmoisture berfungsi sebagai pembaca kelembaban tanah tanaman dan DHT11 berfungsi sebagai pembaca suhu udara disekitar tanaman. Kemudian modul relay berfungsi untuk mengaktifkan dan mematikan pompa air. LCD digunakan untuk tampil hasil data pembacaan dan Modul ESP8266 juga digunakan sebagai tampilan hasil data pembacaan terhadap sensor, yang akan dikirim ke website thingspeak.com.
\end{abstract}

Kata kunci- Arduino Uno, Sensor Soilmoisture, sensor DHT11, Relay, pompa air 12 VDC, modul ESP8266, LCD, website.

\section{Pendahuluan}

Tanaman yang berkualitas dapat dihasilkan dengan memperhatikan perkembangan dan pertumbuhan tanaman, sehingga perlu diperhatikannya kelembaban tanah dan suhu tanaman tersebut. Kelembaban dan suhu tanaman dipengaruhi oleh adanya pengairan terhadap tanaman tersebut, maka dirancang suatu alat yang dapat mengontrol debit air yang dikeluarkan untuk menyiram tanaman tersebut. Disamping itu, alat tersebut dapat meringankan pekerjaan manusia tanpa harus menghambat aktifitas lainnya, yaitu dengan menggunakan sensor kelembaban tanah, suhu dan website sebagai media penyampaian informasi dan kontrolnya, sehingga dari jarak jauh pun kita masih dapat melakukan aktifitas seharihari tanpa harus melakukan pekerjaan secara manual yang dapat menghabiskan waktu cukup lama [1].

Penyiraman pada tanaman dengan kelebihan atau kekurangan air dapat pula mengurangi daya tahan maupun menyebabkan kematian pada tanaman itu sendiri. Sehingga berpotensi kerugian pada petani tanaman. Perkembangan teknologi terutama personal computer (PC) sudah demikian berkembang memasuki setiap bidang kehidupan. Pemanfaatan teknologi modern pada bidang pertanian diharapkan dapat meningkatkan hasil pertanian terutama budidaya tanaman [2].

Untuk itu penelitian ini diperlukan untuk suatu sistem yang dapat mengontrol peyiraman tanaman secara otomatis dan efesien dalam penggunaan waktu.

\section{Strawberry}

Didaerah tropis seperti Indonesia, tanaman strawberry akan tumbuh dan berkembang dengan cukup baik didaerah dengan ketingian lebih dari 600 mdpl (dari permukaan laut). Diketinggian ini suhu udara pada $28^{\circ} \mathrm{C}$ pada suhu yang dingin dan kelembaban relative yang besar sekitar 60 $80 \%$, perkembangan strawberry tidak akan mengalami stress jika kebutuhan air cukup.

\section{Arduino Uno}

Mikrokontroler yang menggunakan ATMega328 biasa digunakan pada Arduino Uno. ATMega328 terdiri dari input/output 14 pin (6 pin sebagai PWM), analog input 6 pin, $16 \mathrm{MHz}$ osilator kristal, koneksi USB, power jack, ICSP header, dan tombol reset. ATMega328 mempunyai fungsi yang banyak diperlukan untuk mikrokontroler, mudah menghubungkannya ke sebuah laptop dengan kabel USB atau supply dengan menggunakan adaptor AC menjadi DC atau memakai powerbank untuk memulainya [3][4]. 


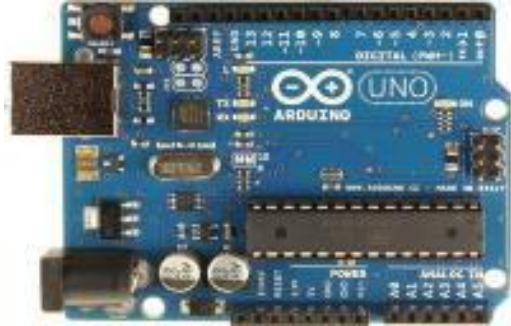

Gambar 1. Arduino Uno

\section{Liquid Crystal Display (LCD)}

Liquid Crystal Display (LCD) adalah jenis monitoring yang digunakan untuk menampilkan karater-karakter baik berupa angka, huruf, simbol dan sebagainya, LCD digunakan untuk moniroting hasil data pembacaan sensor yang digunakan [5].

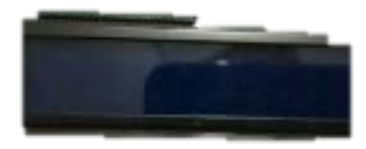

Gambar 2. Liquid Crystal Display (LCD)

\section{Sensor Soilmoisture}

Soilmoisture berbentuk huruf $\mathrm{U}$ yang merupakan lempengan konduktor logam yang sangat sensitive terhadap muatan listrik dalam media tanah. Media yang akan menghantarkan tegangan analaog berupa listrik yang nilai nya antara 3,3-5volt yaitu dua lempeng konduktor logam dan tegangan pada logam tersebut diubah dari analog menjadi digital untuk diproses oleh sistem [6].

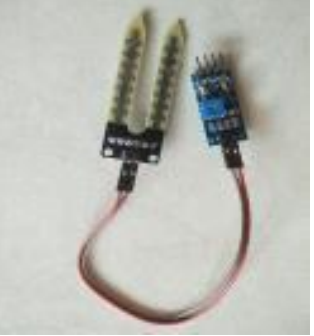

Gambar 3. Soil Moisture Sensor

\section{Sensor DHT}

Sensor yang dapat memberikan informasi kelembaban dan suhu merupakan fungsi dari DHT11. DHT11 merupakan komponen yang stabil jika diprogram menggunakan mikrokontroler ATmega. Kalibrasi yang sangat akurat dan harga terjangkau untuk DTH11. Kalibrasi disimpan pada OTP program memori, saat sensor internal mendeteksi suhu atau kelembaban maka akan membaca hasil kalibrasi yang disimpan tersebut.

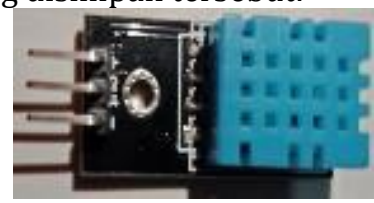

Gambar 4. DHT11

\section{Modul ESP8266}

Modul Wifi salah satunya merupakan ESP8266 yang memiliki harga yang relative rendah dan sesuai digunakan untuk tugas mikrokontroler yang memerlukan fungsi Wifi sebagai sambungan serial UART. Modul Wifi dapat dipogram untuk bertindak sendiri tanpa tambahan mikrokontroler. Modul ini memiliki dua pin GIO, satu pasang pin UART, satu pin CH_PD, pin VCC 3,3V dan pin GND. ESP8266 dapat diprogram menggunakan applikasi Arduino-IDE dan dapat juga menggunakan Bahasa C Arduino, dengan cara melalukan update firmware terlebih dahulu.

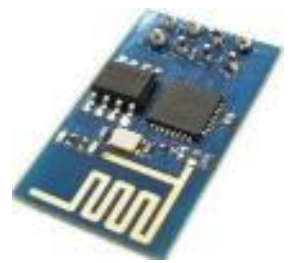

Gambar 5. Modul ESP8266

Relay

Saklar otomatis yang bergerak oleh arus merupakan relay. Mempunyai gulangan bertegangan rendah yang digulung pada suatu inti. Memiliki lempeng besi yang ditarik mengarah keinti saat arus melalui gulungan/kumparan. Lempengan ini terdapat pada sebuah tuas berpegas. Saat lempeng ditarik, jalur kontak Bersama dapat berpindah posisinya dari kontak normal-menutup ke kontak normal-membuka [7].

Motor AC dapat dikontrol menggunakan rangkaian DC atau dengan beban tegangan sumber yang tidak sama antara rangkaian tegangan pengontrol dan tegangan beban merupakan fungsi dari Relay. Mengontrol mengaktifkan/menonaktif beban dengan sumber tegang yang tidak sama merupakan fungsi dari Relay. Berfungsi sebagai pemilih hubungan, untuk penggarap rangkaian delay (tunda), untuk pemutus arus pada kondisi tertent merupakan fungsi dari Relay.



Relay mempunyai sifat antara lain :

1. Tebalnya kawat yang dipergunakan serta banyaknya jumlah lilitan mempengaruhi impendasi kumparan. Agar mempunyai daya hantar yang baik, impedansi biasanya bernilai 1-50 $\Omega$.

2. Nilai tegangan dikalikan arus merupakan daya yang dipergunakan untuk menjalankan relay. 
3. Tergantung pada kontak dan jenis relaynya kontak jangkar bisa menutup dan membuka lebih dari satu kontak secara bersamaan. Besarnya tegangan maksimum jarak antara kontak-kontak sesuai dengan yang diizinkan antara kontak tersebut.

\section{Pompa Air DC}

Motor atau makanisme yang berfungsi untuk menghisap cairan dari tempat yang rendah ke tempat yang lebih tinggi atau berfungsi untuk menaikkan tekanan cairan dari cairan tekanan rendah ke cairan yang tekanan tinggi dan berfungsi juga sebagai penguat jalannya laju pada suatu jaringan sistem berpindah merupakan fungsi dari pompa air. Mekanisme ini diraih dengan mengubah dari tekanan yang rendah pada sisi masukan atau penghisapan dari tekanan yang tinggi pada sisi keluaran atau pelepasan dari pompa.

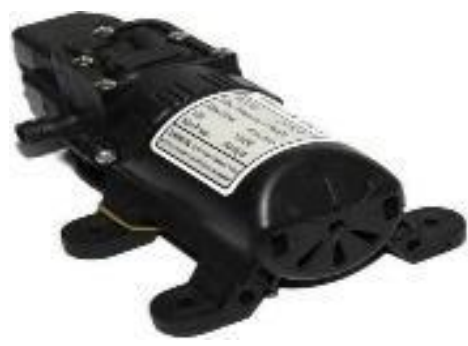

Gambar 7. Pompa Air DC

\section{Website}

Web yang memiliki sejumlah halaman berbagai topik yang saling berhubungan, biasanya disertai juga dengan gambar, video, atau jeni-jenis berkas lain-lainya merupakan pengertian Webstie. Website diletakkan pada suatu webserver yang dapat diakses menggunakan jaringan seperti internet, atau juga jaringan wilayah local (LAN) melalui alamat internet yang dikenali sebagai URL.

Website dibagi kedalam dua kategori, yaitu static website dan dynamic website.

1. Static Website adalah website yang mempunyai konten yang statis atau tidak berubah-ubah.

2. Dynamic website

Website dengan yang kontennya yang berubah-ubah merupakan pengertian dari website dynamic. Aplikasi dari website dinamis banyak ditemukan diinternet, misalnya dalam portal berita, situs social networking, blog dan lain sebagainya [8].


Gambar 8. Thingspeak.com

\section{Flowchart (Diagram alir)}

Urutan perintah program pada suatu diagram merupakan pengertian flowchart. Secara langsung menunjukkan pengontrol Algoritma, yaitu sebagai untuk rangkaian pelaksanaan kegiatan yang juga merupakan fungsi flowchart. Untuk mejelaskan setiap tahap demi tahap penyelesaian kendala secara sederhana, rapi, terurai dan jelas dengan memakai simbol-simbol standar merupakan tujuan flowchart.

Berikut simbol-simbol dari flowchart antara lain sebagai berikut:

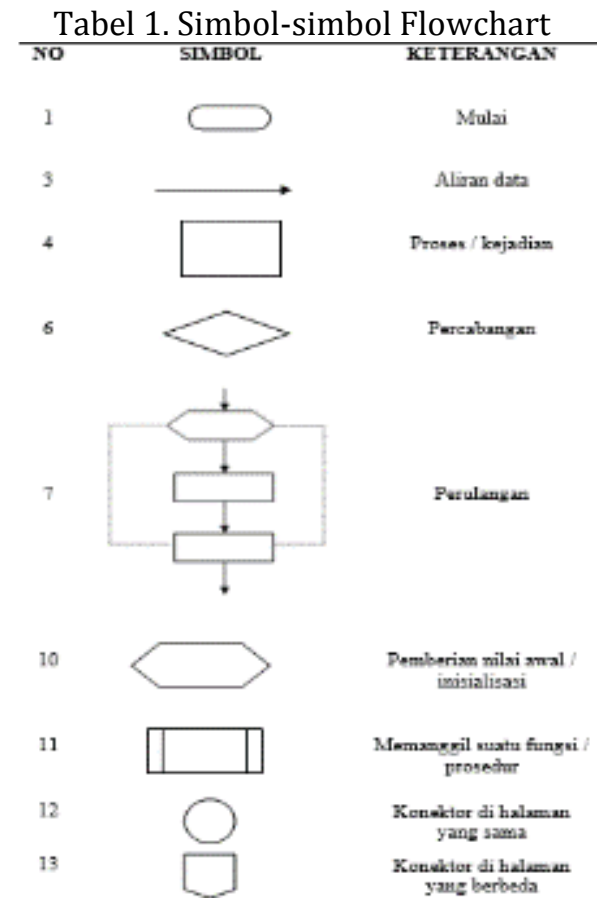

\section{METODE}

\section{Blog Diagram}

Blog diagram menjelaskan bagaimana alat bekerja sesuai dengan sebab dan akibat antara masukan dan keluaran.

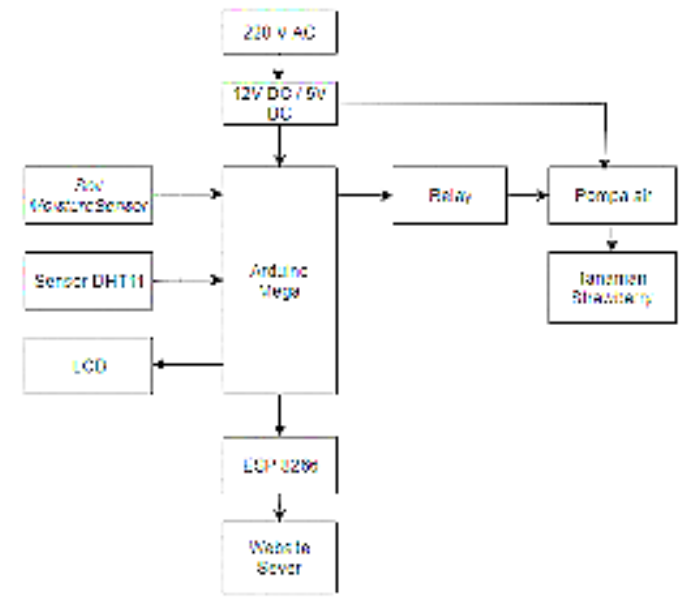

Gambar 9. Block Diagram 


\section{Perancangan Perangkat Keras}

Perancangan ini bertujuan untuk mengetahui komponen elektronika apa saja yang digunakan pada perancangan alat. Berikut komponen yang digunakan:

1. Catu daya

2. Arduino Uno

3. Soil Moisture Sensor

4. Sensor DHT11

5. Relay

6. Modul ESP8266

7. LCD

8. Pompa Air DC

Adapun mekanik perancangan alat sesuai dengan gambar dibawah ini.

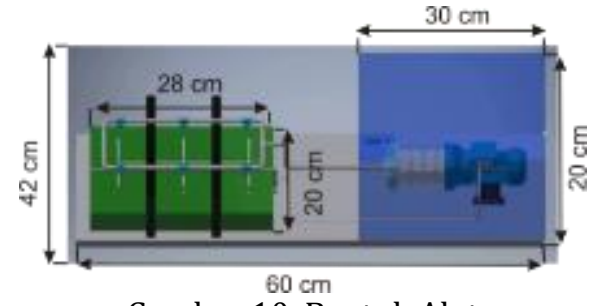

Gambar 10. Bentuk Alat

\section{Flowchart Sistem}
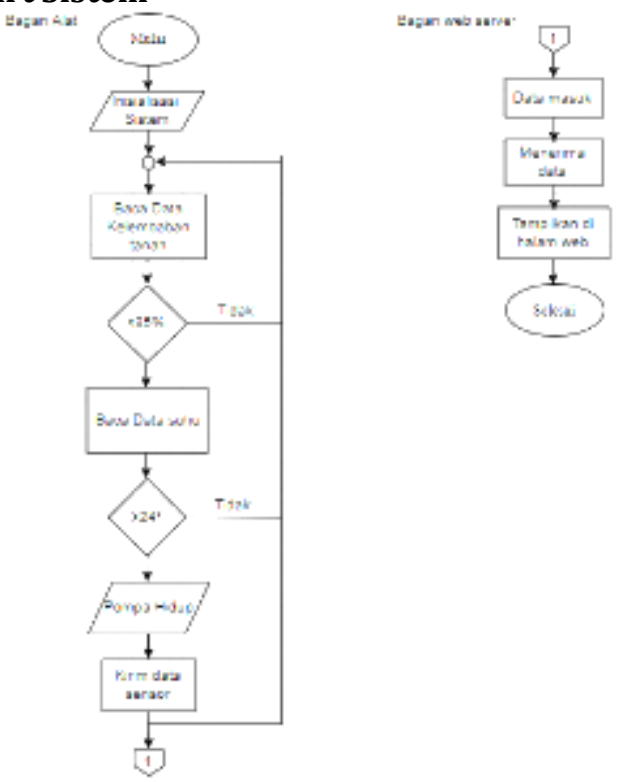

Gambar 11. Flowchart

\section{HASIL DAN PEMBAHASAN}

Untuk membuktikan apakah alat berjalan dengan baik maka perlu dilakukan pengujian. Adapun pengujian dilakukan, yaitu : pengujian sensor DHT11, soil moisture sensor, relay dan pompa 12 VDC, sensor ESP8266.

\section{Pengujian Sensor DHT11}

Sensor DHT11 digunakan untuk mendeteksi suhu udara disekitar tanaman. Sensor DHT11 dipasang didekat tanaman strawberry sebagai objek penelitian. Untuk mengetahui suhu, dilakukan percobaan pada siang dan malam hari dan didapatkan hasil seperti dibawah ini.
Tabel 2. Data nilai pengukuran DHT11

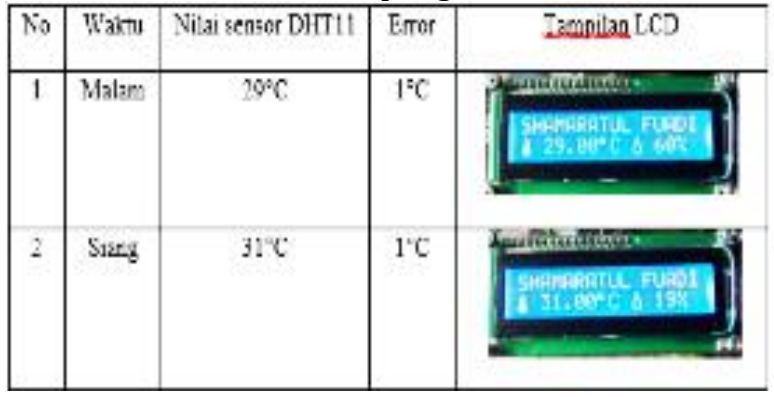

Pada pengujian nilai suhu dari Sensor DHT11 dan alat ukur termometer menunjukan perbedaan pengukuran yang tidak terlalu jauh.

\section{Pengujian Sensor Soilmoisture}

Sensor Soilmoisture digunakan untuk mendeteksi kelembaban tanah. Sensor Soilmoisture ditancapkan pada tanah tanaman strawberry. Untuk mengetahui kelembaban tanah, dilakukan percobaan pada tanah kering dan basah yang mehasilkan data seperti dibawah ini.

Tabel 3. Data nilai pengukuran soilmoisture

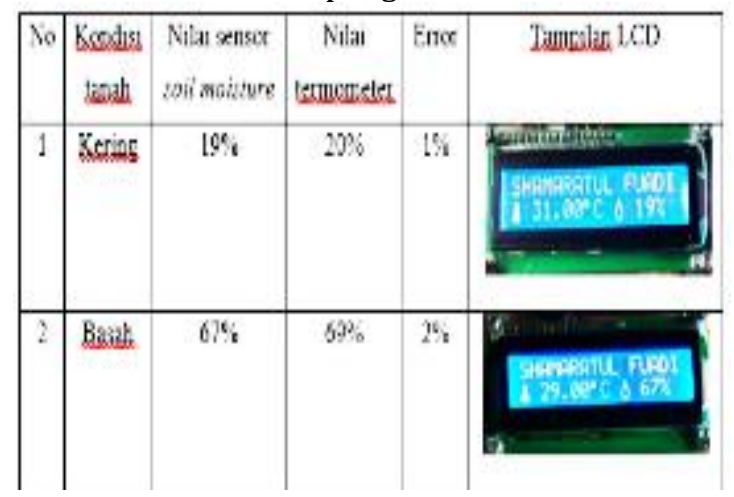

\section{Pengujian Relay dan pompa air 12 VDC}

Pengujian menggunakan modul relay berfungsi untuk mengetahui, apakah modul relay bekerja dengan baik atau tidak. Modul relay dapat bekerja pada tegangan 5 volt, Agar dapat melakukan pengujian maka perlu dibuat program modul relay, sensor, motor dan Arduino. Program tersebut dapat dibuat pada software arduino IDE.

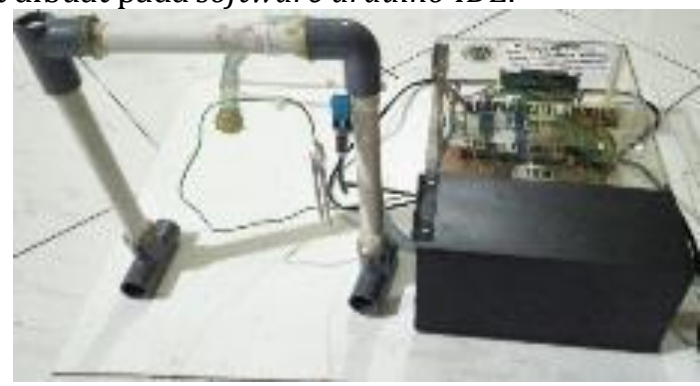

Gambar 12. Pengujian Relay dan pompa air 12 VDC

Pada pengujian diatas, relay akan mengaktifkan pompa air jika suhu besar dari $28^{\circ} \mathrm{C}$ dan kelembaban kecil dari $60 \%$. 


\section{Pengujian Modul ESP8266}

Pengujian modul ESP8266 dengan tujuan mengetahui apakah modul ESP8266 berkerja dengan baik melakukan pengiriman data kewebsite yang dituju. Hasil pengujian dapat dilihat pada tampilan dibawah ini.

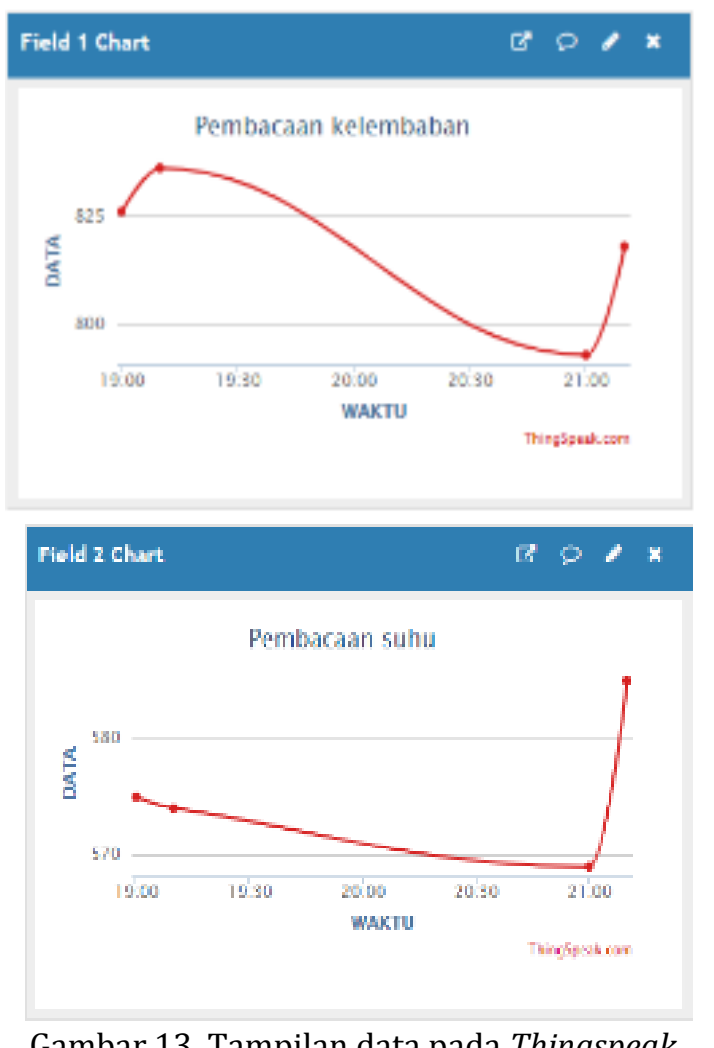

Dari pengujian modul ESP8266, dapat diketahui modul ESP8266 melakukan pengiriman data dengan sangat baik.

\section{PENUTUP}

Berdasarkan hasil pengujian hardware dan software pada alat Prototype Alat Penyiram Tanaman Strawberry Otomatis Dengan Sensor Kelembaban Dan Suhu Berbasis Arduino maka dapat diperoleh kesimpulan seperti akan dijelaskan dibawah ini :

Prototype alat penyiram tanaman strawberry otomatis dengan sensor kelembaban dan suhu yang telah selesai dibuat berhasil dengan baik. Program soilmoisture dan DHT11 yang telah dibuat sesuai dengan prinsip kerja alat dan berjalan dengan baik. Berdasarkan pengujian alat, alat berfungsi dengan cukup baik dan pengiriman data dapat berfungsi dengan cukup baik sesuai yang diprogram

\section{REFERENSI}

[1] Risfendra, 0. Candra, Syamsuarnis, and Firman, "Teaching Aid Development of Elecropneumatic Based Automation Course," in Advances in Social Science, Education and Humanities Research, 2019, vol. 299, no. Ictvet 2018, pp. 214-217.

[2] A. Adriansyah and O. Hidyatama, "Rancang Bangun Prototipe Elevator Menggunakan Microcontroller Arduino Atmega 328p," J. Teknol. Elektro, vol. 4, no. 3, 2013.

[3] S. Zholehaw, A. B. Pulungan, and Hamdani, "Sistem Monitoring Realtime Gas Co Pada Asap Rokok Berbasis Mikrokontroler," JTEV, vol. 5, no. 1, pp. 17-22, 2019.

[4] Alldatasheet, "Datasheet Mikrokontroller ATMega32," https://www.alldatasheet.com/, 2020. [Online]. Available: https://www.alldatasheet.com/.

[5] F. F. Arief, M. Muchlas, and T. Sutikno, "Kompas Digital Dengan Output Suara Berbasis Mikrokontroler At89S52," TELKOMNIKA (Telecommunication Comput. Electron. Control., vol. 6, no. 1, p. 1, 2008.

[6] I. Risqi, "Rancang Bangun Alat Pengaman Kendaraan Roda Empat Menggunakan Sensor RFID Berbasis Mikrokontroler Arduino UNO," Universitas Negeri Padang, 2017. M. A. Heryanto and W. Adi, Pemograman Bahasa C untuk Mikrokontroler ATMEGA 8535. Yogyakarta: Andi Yogyakarta.

[8] N. Jalinus, F. Rizal, R. E. Wulansari, M. A. Zaus, and S. Islami, “Design and Need Analysis of Computer Devices' Expert System using Forward Chaining Method," Int. J. GEOMATE, vol. 17, no. 61, pp. 202-206, 2019. 